$$
\text { CONF- } 960826--1
$$

Submitted for publication in J. Thermal Analysis, ICTAC 1996 Proceedings

\title{
MULTIPLE MELTING PEAK ANALYSIS WITH GEL-SPUN ULTRA-HIGH MOLAR MASS POLYETHYLENE
}

\section{Andreas Boller and Bernhard Wunderlich*}

Department of Chemistry, The University of Tennessee, Knoxville, TN 37996-1600, and

$$
\begin{aligned}
& \text { Chemistry and Analytical Sciences Division, Oak Ridge National Laboratory, } \\
& \text { Oak Ridge, TN 37831-6197, USA } \\
& \text { DEC } 191983
\end{aligned}
$$

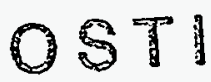

Abstract

The multiple melting peaks observed on differential scanning calorimetry (DSC) of ultrahigh molar-mass polyethylene fibers (UHMMPE) are analyzed as a function of sample mass. Using modern DSC capable of recognizing single fibers of microgram size, it is shown that the multiple peaks are in part or completely due to sample packing. Loosely packed fibers fill the entire volume of the pan with rather large thermal resistance to heat flow. On melting, the fibers contract and flow to collect ultimately at the bottom of the pan. This process seems to be able to cause an artifact of multistage melting dependent on the properties of the fibers. A method is proposed to greatly reduce, or even eliminate, errors of this type. The crucial elements of the analysis of melting behavior and melting temperature are decreasing the sample size and packing the individual fibers in a proper geometry, or to introduce inert media to enhance heat transport.

Keywords: differential scanning calorimetry, DSC, polyethylene, fiber, double melting peak

"The submitted manuscript has been
authored by 2 contractor of the U.S.
Govemment under the contract No.
DE-AC05-960R22464. Accordingly,
the U.S. Govemment retains a non-
exclusive, royalty-free license to pub-
lish, or reproduce the published form
of this contribution, or allow others to
do sa, for U.S. Government purposes."

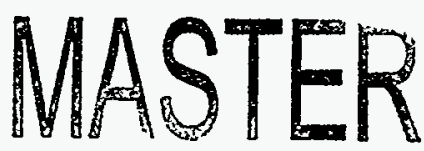

DISTRIBUTHON OF THIS DOCUMENT IS UNLAHTED

lan 


\section{DISCLAIMER}

Portions of this document may be illegible in electronic image products. Images are produced from the best available original document. 


\section{DISCLAIMER}

This report was prepared as an account of work sponsored by an agency of the United States Government. Neither the United States Government nor any agency thereof, nor any of their employees, makes any warranty, express or implied, or assumes any legal liability or responsibility for the accuracy, completeness, or usefulness of any information, apparatus, product, or process disclosed, or represents that its use would not infringe privately owned rights. Reference herein to any specific commercial product, process, or service by trade name, trademark, manufacturer, or otherwise does not necessarily constitute or imply its endorsement, recommendation, or favoring by the United States Government or any agency thereof. The views and opinions of authors expressed herein do not necessarily state or reflect those of the United States Government or any agency thereof. 


\section{Introduction}

The interpretation of differential scanning calorimetry (DSC) on melting of ultra high molar mass polyethylene (UHMMPE) fibers has been the focus of much research [1-11]. Multiple melting peaks were described for such fibers in many of the cited papers. The multitude of different polyethylenes has led to the publication of many different, often conflicting reports on the shape and position of one or more melting peaks. Equilibrium crystals have an extended-chain macroconformation and show only a single, sharp melting point when measured without superheating (i.e. under equilibrium conditions) [12]. For the understanding of materials properties and the correlation of DSC with other experimental methods, it is important to clarify the true nature of the transition for any given sample. The experimental verification of a single, sharp melting peak of melting of polyethylene under equilibrium conditions indicates that multiple melting peaks must be due to irreversible effects. Irreversible processes may have their origin within the sample or be an instrumental effect, caused by the dynamic nature of DSC.

Double melting peaks in polyethylene can have several causes. Two peaks have been observed when there is an initial transition from the low-temperature, orthorhombic phase to the high-temperature, hexagonal phase before ultimate isotropization. If monoclinic and orthorombic polymorphs of polyethylene were present in a sample, they may also give rise to two melting peaks. Alternatively, the lower endotherm can be due to the melting of thin, lamellar crystals, while the higher melting component may be thicker lamellae or even extended chain crystals. A combination of endothermic and exothermic events occurring simultaneously in the melting region, as in melting followed by recrystallization to more stable crystals, can also produce double peaks in a DSC experiment. These double melting peaks are non-equilibrium processes. They are common in 
polyethylene as well as in other polymeric samples [12]. It will be shown, however, that all these possible effects play a minor role in the isotropization of gel-spun and ultra-drawn UHMMPE fibers.

Previously we studied the same fibers by a combination of techniques. Small angle X-ray diffraction and full-pattern wide-angle X-ray diffraction for structure analysis, solid state NMR spectroscopy for a check of large-amplitude motion, optical microscopy to qualitatively visualize the shrinkage behavior, and DSC experiments to see the progress of melting [13]. It was shown that the crystals of the fibers were orthorhombic with only small amounts of the monoclinic polymorph. Only a very small fraction contributed to small-angle $\mathrm{X}$-ray diffraction peaks that could be interpreted as lamellae of unique thicknesses. In addition to the crystals, an intermediate phase could be identified. The intermediate phase is highly oriented and intermediate in mobility between crystalline and amorphous polyethylene. Finally, a small amount of random amorphous material was detected.

To understand the mechanical properties, it was important to know the structure and degree of orientation of the intermediate phase. Since the intermediate phase cannot be realized independent of the crystals, it was concluded that the intermediate phase is constrained by the crystals. We observed double melting peaks characteristic of the processing conditions of the fibers, as were reported before for similar samples $[2,7,9]$. Since no significant amounts of monoclinic or hexagonal crystals were found, polymorphism could not be at the root of the double peak. Since no lamellae were present, this could also not be a reason for the double peak. Finally, since the melting peak areas did not change with heating rate, and it was possible to separate the melting peaks by partial melting, no dynamic recrystallization could be the cause for the double peak. We assigned, thus, the two melting peaks to orthorhombic crystals with different degrees of restraint to the 
surrounding intermediate, oriented phase [13]. This solution is not fully satisfying since no clear evidence of a bimodal distribution of crystal sizes could be found from the wide- and small-angle $\mathrm{X}$-ray data. It will be shown in this paper that a much simpler interpretation is possible. The double melting peak is an instrumental effect and can be made to disappear by changing the experimental conditions.

Multiple peaks as an effect of instrumental conditions have been studied earlier [14] using a Perkin-Elmer power-compensation DSC. It was shown that the alignment of small indium pieces along the diameter of the sample pan could produce multiple melting peaks. The one-dimensional non-uniform distribution of the sample inside the pan in such an experiment may well correspond to the three-dimensional, non-uniformity of fibrous samples. The effects of such non-uniform sample arrangement with respect to the DSC sensors has to be considered in special cases. They can be minimized with different instrumental designs. Both a multiple thermocouple design (MettlerToledo) or a sensor larger than the sample pan (TA Instruments) are self-averaging and lessen the effects of the horizontal non-uniformity. In this paper it will be shown, that in addition to the positioning of the sample, one also needs to analyze the change in packing when dealing with the melting behavior of fibrous UHMMPE. Some of the findings of earlier studies are possibly in need of reevaluation in the light of the presented research.

\section{Experimental Details}

A commercially available Mettler-Toledo DSC820 module, equipped with a ceramic sensor and sample changer was used in the research. Dry nitrogen gas with a flow rate of $10 \mathrm{~mL} / \mathrm{min}$ was purged through the cell. The gas flow rate was monitored and adjusted with a gas controller. All 
mass determinations were carried out on a Cahn C-33 electrobalance with a sensitivity of $1 \mu \mathrm{g}$ and an overall accuracy of $\pm 0.001 \%$ of the overall load (sample and pan of ca. $50 \mathrm{mg}$ ).

The samples for the temperature calibration were: indium ( $429.7 \mathrm{~K})$, naphthalene ( 353.42 $\mathrm{K}), n$-octane $(116.4 \mathrm{~K})$, acetone $(177.9 \mathrm{~K})$, cyclohexane s/s (186.09 K), cyclohexane $\mathrm{s} / 1(297.7 \mathrm{~K})$, cycloheptane $(265.1 \mathrm{~K})$, tin $(505.05 \mathrm{~K})$. The onset of melting was determined by extrapolation of the melting peak to the baseline, the end of the melting peak by extrapolation of the hightemperature side of the peak to the baseline.

Four highly drawn PE fiber samples were included in this study. These were gel-spun UHMMPE fibers [15-17] and were provided by Allied-Signal Inc. All samples had similar molar masses $\left(\mathrm{M}_{\mathrm{w}}>10^{6}\right)$. One of them (PE-I) is a research sample. The samples PE-II and PE-III are identical to the commercially available Spectra 1000 and 900 fibers. Different processing (drawing and annealing) make these fibers have different properties. A fourth sample, PE-IV, is the same gelspun fiber as PE-I, but without further processing. The same fibers, together with other samples were also included in the earlier study [13].

The fibers were either encapsulated in a $40 \mu \mathrm{L}$ standard aluminum crucible without a center pin and with the cover lid cold welded, or the fibers were placed in an open pan for ease of visual observation of the appearance after melting. In separate experiments, fiber samples were embedded in anhydrous aluminum oxide for enhanced thermal conductivity. Sample masses varied from 24 $\mu \mathrm{g}$ to $4 \mathrm{mg}$. The reference pan was identical for all measurements. In the optimal arrangement each fiber is in direct contact with the bottom of the pan, which requires sample preparation under the microscope and leads to masses that range from of 0.02 to $0.10 \mathrm{mg}$. 


\section{Results}

Figure 1 shows the melting of UHMMPE fibers measured with parameters such as those commonly used in the literature $[1,7,8,11]$, namely 3 to $5 \mathrm{mg}$ mass and a heating rate of $10 \mathrm{~K} / \mathrm{min}$ in crimped aluminum pans. These data were measured with a standard TA Instruments 912 DSC as described in Ref. [13]. The melting shows clear double peaks and the temperature range is rather broad. The difference between onset of melting and the end of the peak is of the order of $10-25 \mathrm{~K}$. The new results of DSC experiments on PE-III in uncrimped pans as a function of sample mass is shown in Fig. 2. The peak shape at the lowest mass of 24 micrograms has no double melting peak. The increase in mass gradually introduces two effects, first a broadening of the melting peak, then the development of shoulders and secondary peaks. At masses over $3 \mathrm{mg}$ the shapes shown in Fig. 1 are reached. A graphic representation of the temperatures of onset, peak, and end of the peak is shown in Figs. 3A and B for the first melting and on second and third heatings after cooling from the melt at about $40 \mathrm{~K} / \mathrm{min}$. It is clearly visible that in the first heating runs the onset temperature varies only within the experimental repeatability. The peak temperature and the end of the peak are, however, much smaller for the 24 microgram sample, as can also be seen from Fig. 2. Its melting range is only about $3 \mathrm{~K}$. The second and third runs, in contrast, show a much lower onset of melting and little change in melting range with sample size, an indication of inherent broadness of melting.

The melting peak areas are shown in Figs. 3C and D. They indicate a trend to smaller values for smaller masses. The $100 \%$ value was taken from the heat of fusion of completely crystalline polyethylene (293 J/g) [18]. At the smaller masses weighing errors start to be significant. Therefore, the absolute values for the transition enthalpies are less accurate for the smaller samples and only the peak shapes should be used to discuss the melting kinetics. 
In order to determine whether the differences between the smaller and larger sample are caused by insufficient heat conduction, a test was performed in which a sample of approximately $1 \mathrm{mg}$ of PE IV fiber was packed into the sample pan with layers of powdered, anhydrous aluminum oxide. By utilizing this method, the thermal conduction to the top of the fiber sample is assured. Figure 4 is the result. Only one single peak is observed on both, first and second heating. As for the small sample of PE III in Fig. 2, the melting peak on first heating is much narrower than in Fig.1, and the second run corresponds to Fig. 3B.

\section{Discussion}

The analysis of the melting behavior of UHMMPE fiber samples in Figs. 1 to 4 shows that sample preparation is crucial. Both, the placement of single layers of fibers at the bottom of the pan or the filling of the spaces between the fibers with powdered alumina makes the double melting peaks disappear. This is a strong suggestion that the double melting peaks for UHMMPE gel-spun fibers are artefacts. The rather poor contact of the thin fibers with the pan, their unique contraction on melting, and their slow flow seem to provide not only the reason for an interrupted melting and broader melting peak, but also the reproducible differences for the different types of fibers.

Further differences can be introduced by restraining the fibers. The differences between the melting curves in Figs. 1 and 2 for about equal masses are probably due to compression and partial fixing of the fibers after crimping of the pans in the runs shown in Fig. 1. Most examples in the literature were similarly crimped. It is well known that melting of fibers held at constant length have considerably sharper melting peaks [12]. 
The single, rather sharp melting peak of the fibers is much more in line with the structure picture developed earlier [13]. The nanophase-separated, intermediate phase keeps its orientation because of its connection to the crystals by tie molecules. In turn, the tie molecules cause also the superheating of the crystals. In the beginning of melting they hinder the molten molecules to reach a random-coil macroconformations-and thus gain a lesser amount of entropy, which in turn, causes the higher, local melting temperature. As soon as the network of crystals collapses, however, the local melting temperature drops and the melting accelerates, i.e. the peak sharpens.

$$
* \quad * \quad *
$$

This work was supported by the Division of Materials Research, National Science Foundation, Polymers Program, Grant \# DMR 90-00520 and the Division of Materials Sciences, Office of Basic Energy Sciences, U.S. Department of Energy at Oak Ridge National Laboratory, managed by Lockheed Martin Energy Research Corp. for the U.S. Department of Energy, under contract number DE-AC05-96OR22464. Support for instrumentation came from TA Instruments, Inc. and Mettler-Toledo, Research support was also given by ICI Paints.

\section{References}

1) Hoogsteen, W.; ten Brinke, G.; Pennings, A.J. Colloid \& Polymer Science 266, (1988) 1003

2) Pennings, A.J. Journal of Polymer Science Polymer Physics Edition 17, (1979) 1011

3) Smook, J.; Pennings, A.J. Colloid and Polymer Science 262, (1984) 712

4) Rastogi, S.; Odell, J.A. Polymer 34, (1993) 1523 
5) van Aerle, N.A.J.M.; Lemstra, P.J.; Braam, A.W.M. Polymer Communications 30, (1989) 7

6) Saraf, A.W.; Desai, P.; Abhiraman, A.S. Journal of Applied Polymer Science: Applied Polymer Symposium 47, (1991) 67

7) Hsieh, Y.; Ju, J. Journal of Applied Polymer Science 53, (1994) 347

8) Murthy, N.S.; Correale, S.T.; Kavesh, S. Polymer Communications 31, (1990) 50

9) Kanamoto, T.; Hoshiba, T.; Yoshimura, T.; Tanaka, K.; Takeda, M. Rept. Progr. Polym. Phys. Japan 28, (1985) 227

10) Smith, P.; Lemstra, P.J. Journal of Materials Science 15, (1980) 505

11) Bastiaansen, C.W.M; Lemstra, P.J. Makromol. Chem. ,Macromol. Symp. 28, (1989) 73

12) Wunderlich, B.Macromolecular Physics, Volume 3: Crystal Melting; Academic Press: New York, (1980) pp 1-363.

13) Fu, Y.; Chen, W.; Pyda, M.; Londono, D.; Annis, B.; Boller, A.; Habenschuss, A.; Cheng, J.; Wunderlich, B. J. Macromol. Sci. -Phys. B35, (1996) 37

14) Höhne, G.W.H.; Glöggler, E. Thermochim. Acta 151, (1989) 295

15) Smith, P.; Lemstra, P.J.(1983) PATENT US \# 4422993.

16) Kavesh, S.; Prevorsek, D.C.(1983) PATENT US. \# 4413110.

17) Smith, P.; Lemstra, P.J.; Pennings, A.J.(1980) PATENT GERMANY.\# 3004699.

18) Wunderlich, B. and Czornyj, G. Macromolecules, 10, 906 (1977). 


\section{Legends to the Figures:}

Fig. 1 Melting of four $\mathrm{PE}$ fiber samples of $3-5 \mathrm{mg}$ in crimped pans, heated at 10 $\mathrm{K} / \mathrm{min}$ using a TA Instruments 912 DSC [13].

Fig. 2 Melting behavior of PE III (Spectra 900) as a function of mass in coldwelded pans as a function of sample mass.

Fig. 3 Graphic representation of the variation of the onset, peak and end-of-peak temperatures for PE-III as a function of mass in the first run (A) and consecutive second and third runs (B). Peak areas as a percentage of a $100 \%$ crystalline PE sample in the first and consecutive runs are shown in (C) and (D).

Fig. 4 Melting behavior of PE IV heated immersed in anhydrous aluminum oxide powder to facilitate thermal conduction. 


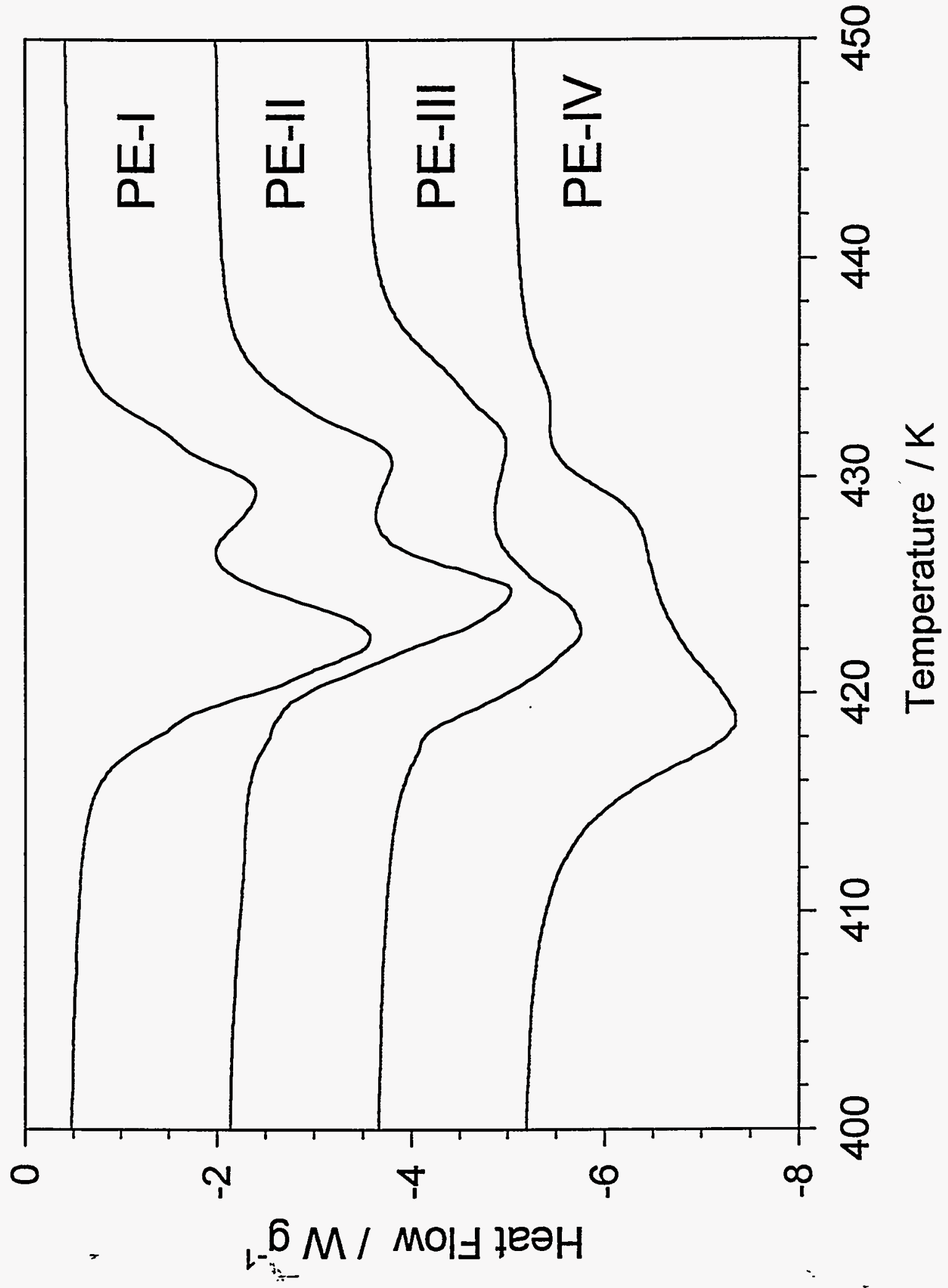

量

$\frac{5}{0}$
$\frac{2}{0}$
$\frac{1}{0}$
$\frac{1}{3}$
$\frac{1}{0}$
$\frac{1}{0}$
m

훈 


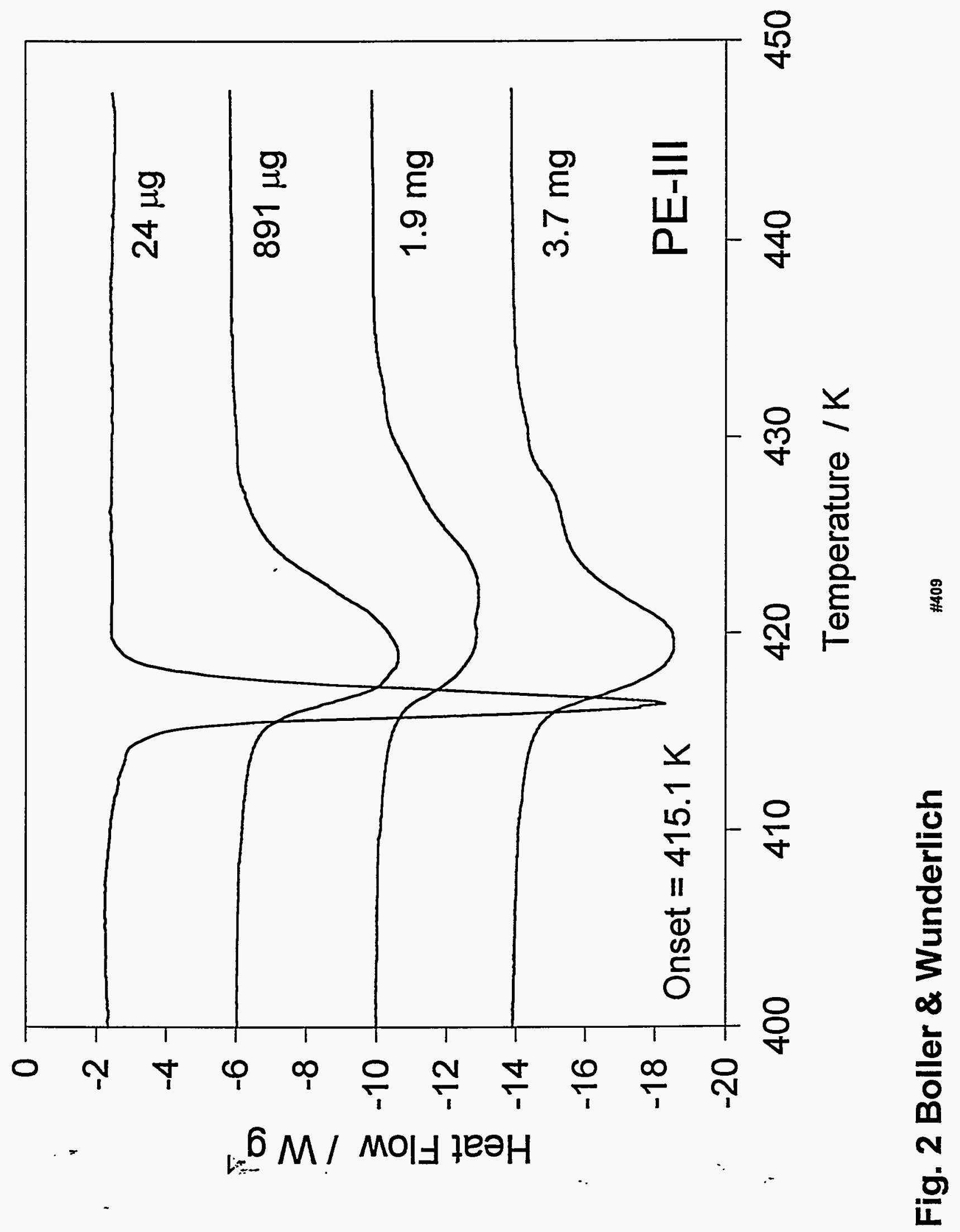



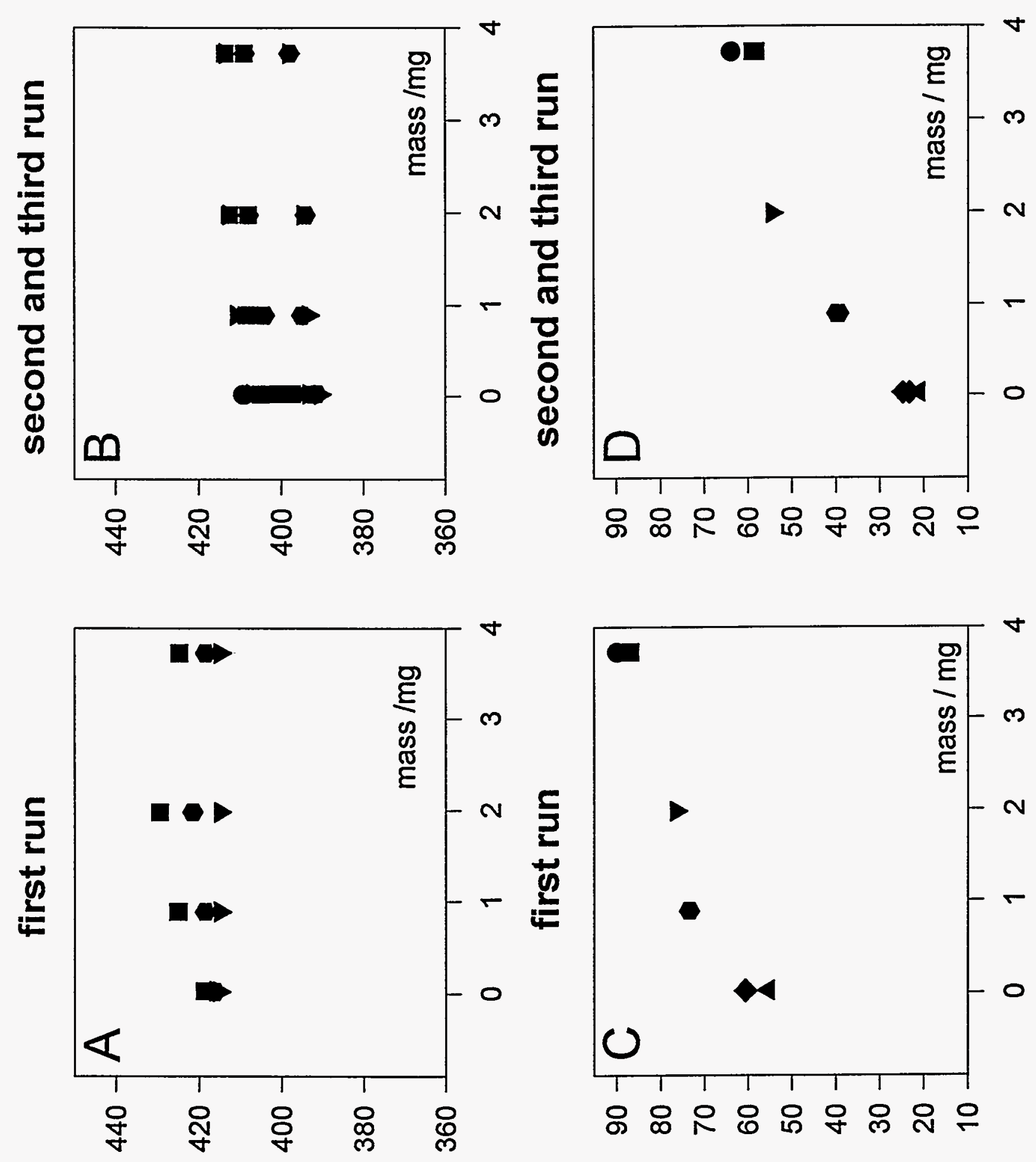

(puə / yead / fosuo) Y $/ 1$

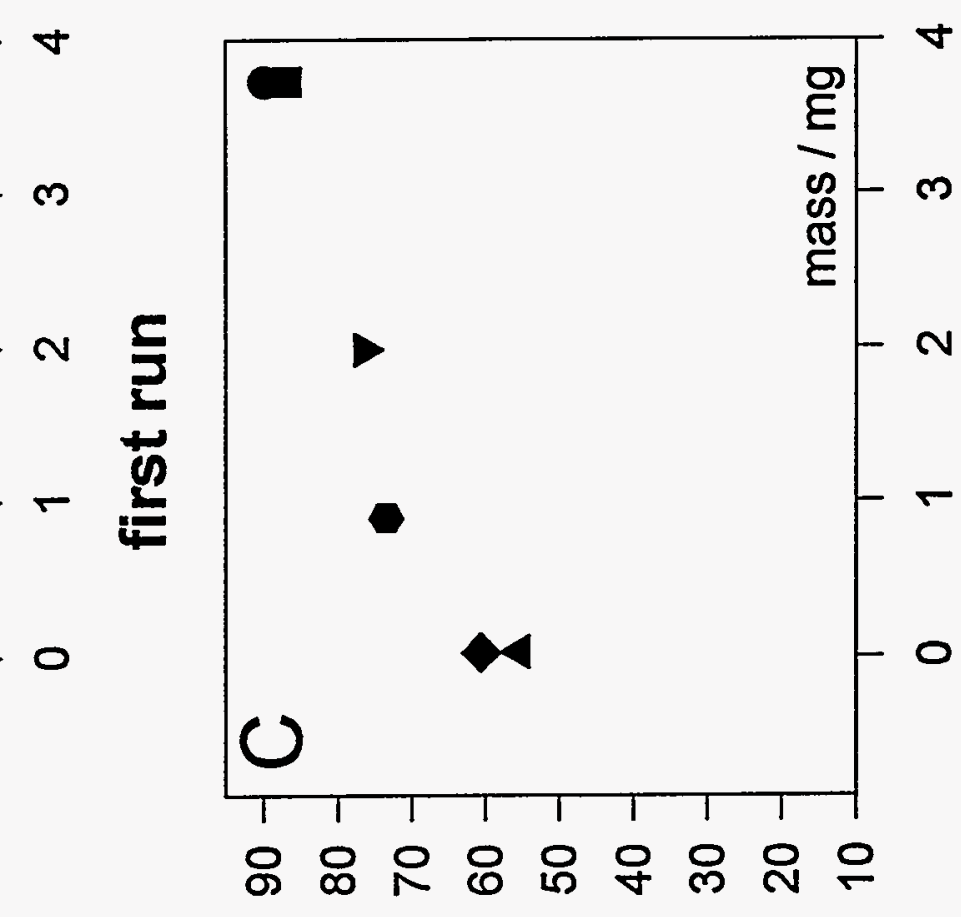

eəse yeəd \%

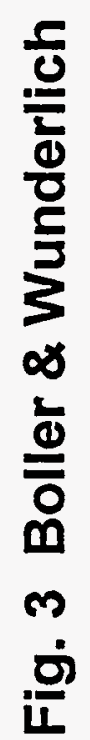




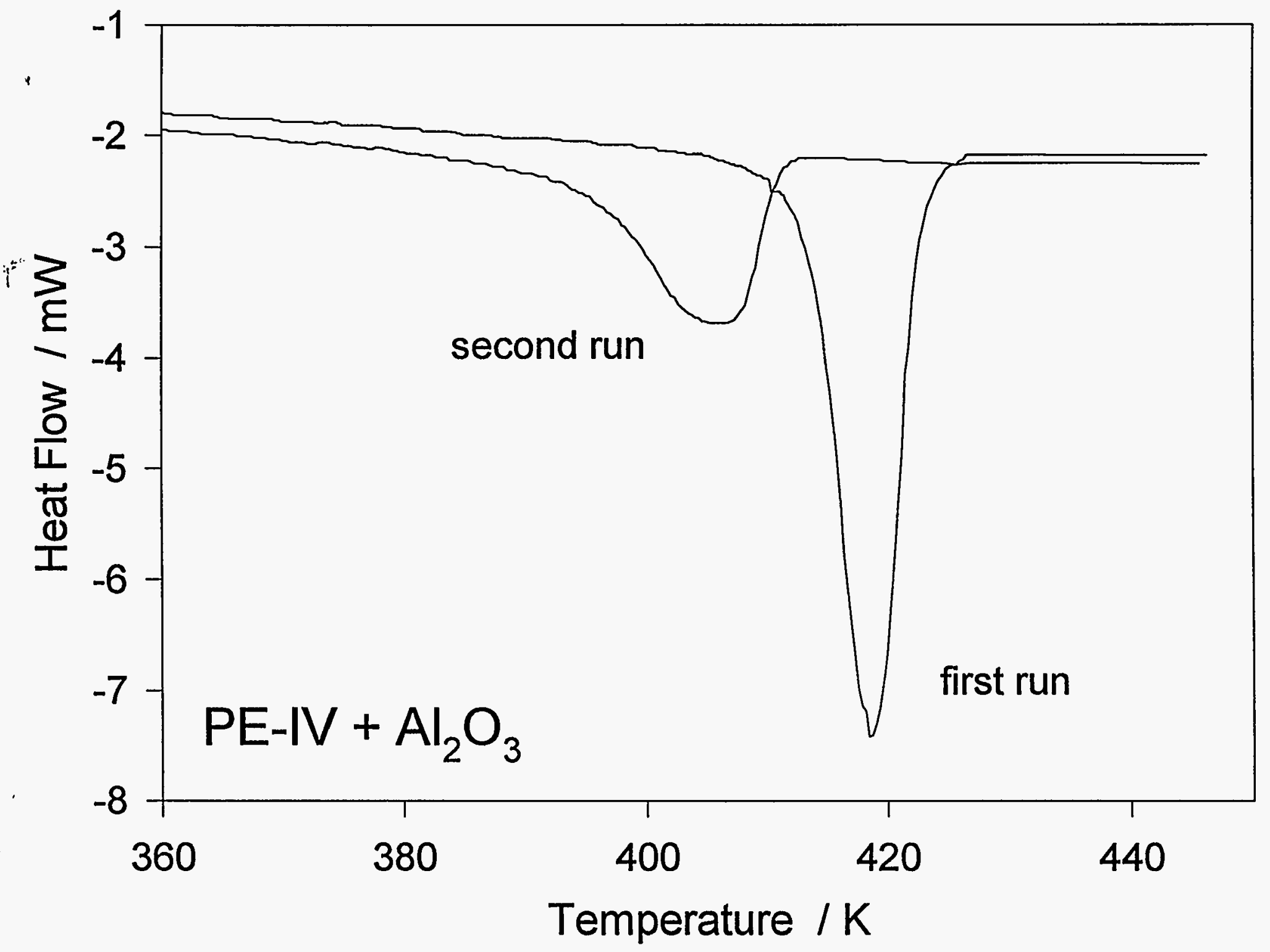

Fig. 4 Boller \& Wunderlich 